\title{
Sistem Cerdas Pengotrolan Gerak Berbasis Random Walk pada Robot Laba-Laba
}

\author{
Yohanes Bowo Widodo*)1), Tata Sutabri ${ }^{2)}$, Vidi Lampah ${ }^{3)}$ \\ ${ }^{13)}$ Program Studi Teknik Informatika, Universitas Mohammad Husni Thamrin \\ ${ }^{2)}$ Fakultas Teknologi Informasi, Universitas Respati Indonesia \\ ${ }^{*}$ Correspondence author: ybowowidodo@gmail.com, DKI Jakarta, Indonesia
}

\begin{abstract}
Abstrak
Robot dapat dikategorikan berdasar bentuk dan fungsinya. Bentuk fisik robot bisa menyerupai manusia atau binatang. Salah satu robot berbentuk binatang adalah robot laba-laba, yang memiliki kaki 4, 6, atau 8 . Random walks merupakan salah satu metode pergerakan robot laba-laba untuk menghasilkan suatu gerakan yang harmonis dan mencapai lokasi tujuan. Dalam penerapannya random walks harus memiliki suatu titik awal sebagai acuan dan titik kestabilan yang harus dipelihara selama bergerak. Teknik random walks pada gerakan robot laba-laba memungkinkan robot bisa bergerak secara leluasa dan berada pada rute yang benar. Sistem sensor digunakan untuk membantu robot dalam mendeteksi adanya halangan yang berada disekitar robot, sehingga halangan tersebut dapat dihindari. Dari hasil percobaan, didapatkan bahwa sistem sensor robot mampu mendeteksi halangan pada jalur robot, dan algoritma random walk dapat menghindari halangan tersebut sehingga mampu mencapai lokasi yang dituju. Tetapi masih terjadi tabrakan pada halangan berupa benda yang berada pada posisi blank spot (area diluar jangkauan sensor).
\end{abstract}

Kata Kunci: Robot, Random Walks, Mikrokontoler, Arduino

\begin{abstract}
Robots can be categorized based on their shape and function. The physical form of a robot can resemble humans or animals. One of the animal-shaped robots is the spider robot, which has 4, 6, or 8 legs. Random walks are a method of spider robot movement to produce a harmonious movement and reach the destination location. In its application random walks must have a starting point as a reference and a point of stability that must be maintained while moving. The random walks technique of spider robot movement allows the robot to move freely and be on the right route. The sensor system is used to assist the robot in detecting obstacles that are around the robot, so that these obstacles can be avoided. From the experimental results, it was found that the robot sensor system is able to detect obstacles in the robot's path, and the random walk algorithm can avoid these obstacles so that it can reach the intended location. But there is still a collision in the form of objects that are in a blank spot position (the area outside the sensor range).
\end{abstract}

Keywords: Robots, Random Walks, Microcontoler, Arduino

\section{PENDAHULUAN}

Riset dalam bidang robotika, saat ini telah berkembang dengan pesat. Hal ini dapat dilihat dari metode-metode yang telah dikembangkan dan diaplikasikan dalam berbagai bidang, seperti bidang kesehatan, pendidikan, sistem keamanan, dan industri. Robot yang sudah diprogram hanya terbatas pada pekerjaan yang sudah diprogram sesuai kegunaan dari robot itu sendiri. Robot hanya bisa bekerja sesuai dengan maksud yang telah diprogram tanpa memperdulikan suatu masalah atau kondisi diluar program yang sudah ditentukan. Dengan pengendali komputer, pergerakan robot menjadi lebih bervariasi karena operasinya bisa diarahkan kepekerjaan baru hanya dengan membuat program baru yang sederhana. Selain itu, dengan adanya sensor maka robot bisa menentukan tindakan cerdas (hampir mirip 
dengan manusia), namun masih ada keterbatasan karena robot hanya bisa bertindak sesuai data yang diperoleh melalui sensor.

Robot laba-laba adalah robot yang termasuk dalam kategori robot berkaki. Robot berkaki banyak digemari karena bentuknya yang unik. Satu kaki pada robot berkaki umumnya memiliki dua sendi / derajat kebebasan atau lebih. Untuk mengatur pergerakan dari kaki robot diperlukan algoritma gerak. Pada robot berkaki, algoritma gerak yang telah lama berkembang di dunia robotika untuk mengontrol gerakan kaki robot adalah tripod gait dan wave gait. Pada algoritma tripod gait, tiga kaki robot mengayun dan tiga kaki lainnya menyentuh tanah secara bergantian untuk membuat robot bisa berjalan sedangakan pada algoritme wave gait, kaki robot bergerak secara bergantian satu persatu seperti gelombang (wave) untuk membuat robot dapat berjalan.

Penelitian terdahulu yang berkaitan dengan materi penelitian ini antara lain adalah sebagai berikut:

Skripsi berjudul "Robot Multi Sensor Sebagai Media Pembelajaran Mata Kuliah Sensor Dan Actuator" meneliti tentang sensor dan aktuator, belum ada media pembelajaran dan setelah dilakukan observasi sebanyak $80 \%$ responden mahasiswa menyatakan belum memahami materi tentang sensor. Dari masalah tersebut kemudian peneliti membuat robot multi sensor yang terintegrasi dan layak digunakan sebagai media pembelajaran pada mata kuliah sensor dan aktuator untuk meningkatkan pemahaman mahasiswa. (Lufita, 2016)

Jurnal berjudul "Aplikasi Sensor Ultrasonik Untuk Deteksi Posisi Jarak Pada Ruang Menggunakan Arduino Uno" meneliti tentang penggunaan sensor ultrasonik untuk mengontrol dan membaca miniatur ruang, yang didalamnya terdapat lilin atau api kecil untuk di padamkan dengan melewati beberapa rintangan dengan cara melintasi lorong dan ruangan yang berbeda. (Arasada \& Suprianto, 2017)

Jurnal berjudul "Perancangan Robot Laba-Laba Pendeteksi Api Berbasis Mikrokontroller ATmega328". Dalam jurnal ini Robot laba-laba yang dibahas adalah robot yang bergerak dengan menggunakan 6 buah kaki dengan 18 motor servo, pengujian terhadap robot dilakukan pada sebuah labirin sederhana untuk mendeteksi adanya api lilin, yang dideteksi oleh sensor panas ketika jarak $100 \mathrm{~cm}$, dan ketika robot berjarak $10 \mathrm{~cm}$ dengan api lilin maka kipas yang digerakan oleh motor DC akan berputar dan memadamkan api lilin hingga api lilin benar-benar padam. Ketika api lilin padam maka kipas akan berhenti berputar dan sistem keseluruhan pergerakan robot laba-laba diatur menggunakan mikrokontroler ATmega328. (Salahuddin \& Mellyssa, 2018) 


\section{METODE}

Robot pada dasarnya di kategorikan berdasarkan jenis dan fungsinya, hal ini bisa dilihat dari bentuk fisik robot yaitu mulai dari bentuk yang menyerupai manusia, binatang, hingga bentuk yang tak beraturan. Salah satu robot berbentuk binatang adalah robot laba-laba, yang memiliki kaki 4, 6, atau 8. Pada penelitian ini dikembangkan robot laba-laba dengan 4 kaki yang bergerak dengan algoritma random walks. Random walks merupakan salah satu metode pergerakan robot laba-laba untuk menghasilkan suatu gerakan yang harmonis dan mencapai lokasi tujuan. Dalam penerapannya random walks harus memiliki suatu titik awal sebagai acuan dan titik kestabilan yang harus dipelihara selama bergerak. Teknik random walks pada gerakan robot laba-laba memungkinkan robot bisa bergerak secara leluasa dan berada pada rute yang benar. Sistem sensor digunakan untuk membantu robot dalam mendeteksi adanya halangan yang berada disekitar robot, sehingga halangan tersebut dapat dihindari.

Random Walks adalah suatu algoritma pengambilan langkah yang dilakukan dalam arah yang acak atau random. Untuk random walks pada kasus satu dimensi (1D) dapat dituliskan, yaitu dengan suatu keadaan yang dapat digambarkan sebagai bilangan integer i $=0, \pm 1, \pm 2, \pm 3, \ldots$ dengan $0<\mathrm{p}<1$, maka Pi, $\mathrm{i}+1=\mathrm{p}=1-\mathrm{Pi}, \mathrm{i}-1$. Hal ini disebut dengan random walks karena dapat dianalogikan dengan langkah manusia dalam satu garis / jalan lurus yang sewaktu-waktu dapat berjalan ke arah kanan dengan probabilitas p dan ke kiri dengan probabilitas 1-p. (Febriani, 2010)

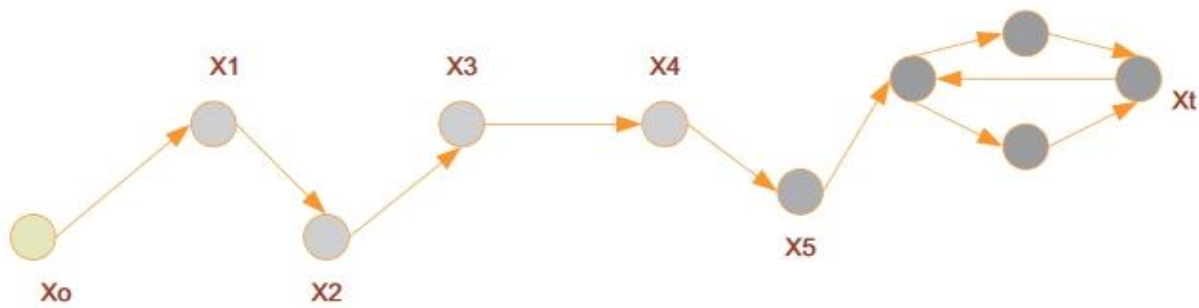

Gambar 1. Gerak secara random walks (sumber: Febriani, 2010)

Dari gambar 1. terlihat adanya pergerakan secara random yang memungkinkan adanya pergerakan balik ke titik sebelumnya pada perpindahan ke Xt. Random Walks yang dibangun pada robot berdasarkan aturan-aturan diantaranya: Terdapat titik awal (starting point). Penentuan titik atau langkah berikutnya dilakukan secara random, yang artinya tidak ada satu arahpun yang memiliki kemungkinan lebih dibandingkan yang lain.

Mikrokontroler merupakan chip yang memiliki bentuk fisik berupa sebuah IC (Integrated Circuit). (Dharmawan, 2017) 


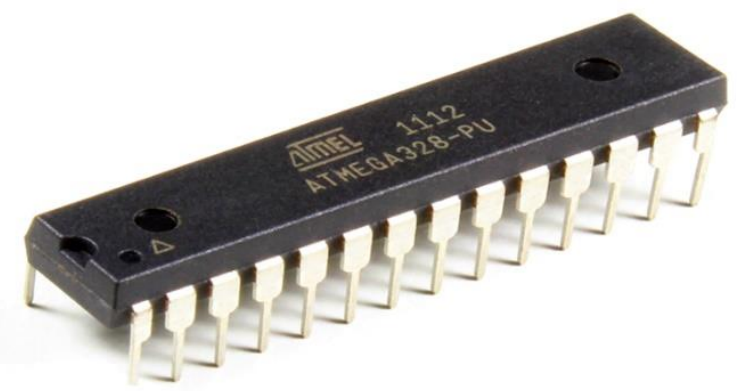

Gambar 2. IC mikrokontroler ATmega328

Sumber : https://www.microchip.com

Mikrokontroler bekerja berdasarkan program yang telah disesuaikan fungsinya dengan kebutuhan yang diinginkan. Program ini ditanamkan langsung kedalam mikrokontroler. Program dalam mikrokontroler ini biasanya terkait dengan pembacaan kondisi diluar mikrokontroler dan pengontrolan perangkat yang terhubung dengan mikrokontroler tersebut. Perangkat-perangkat tersebut bisa berupa sensor atau perangkat aktuator seperti motor servo, motor stepper, saklar atau relay module.

Perangkat-perangkat tersebut terhubung pada kaki-kaki pada mikrokontroler yang berfungsi sebagai I/O port. Kaki-kaki ini bisa berupa input/masukan atau output/keluaran. Port input ini berfungsi sebagai jalur untuk memasukkan data kedalam mikrokontroler. Sedangkan port keluaran berfungsi sebagai jalur untuk mengeluarkan data atau informasi dari mikrokontroler.

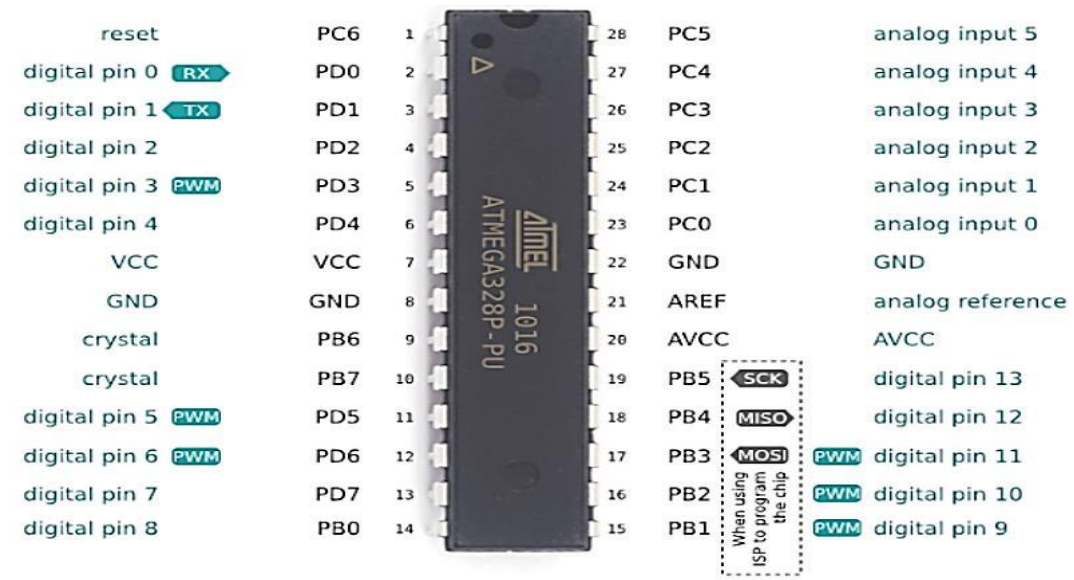

Gambar 2. Pin mapping IC mikrokontroler ATmega328

Sumber : https://www.arduino.cc

Pada jalur masukan (input port), pada umumnya merupakan jalur digital yang hanya mengenal on atau off saja. Contoh penggunaannya adalah untuk mendeteksi kondisi saklar yang terhubung pada jalur masukan apakah dalam keadaan terbuka atau tertutup. Jalur ini kebanyakan adalah jalur digital yang bernilai hidup atau mati (1 atau 0) namun ada 
beberapa mikrokontroler, pada sebagian kaki-kakinya berfungsi untuk mengubah sinyal analog yang masuk pada jalur masukan menjadi bernilai digital. Dengan adanya fitur ini maka sebuah mikrokontroler mampu untuk mengolah data dari sensor-sensor analog sebagai masukannya. Contoh implementasi dari fitur ini pada jalur masukan adalah untuk mengukur besarnya tegangan dari sensor analog misalnya pada sensor HC-SR04. Sedangkan jalur keluaran pada sebuah mikrokontroler dapat digunakan untuk mengendalikan perangkat-perangkat seperti LED, motor, relay dan sebagainya.

Arduino adalah perangkat lunak dan perangkat keras yang ditujukan untuk memudahkan siapa saja agar dapat membuat proyek-proyek elektronika dengan mudah dan cepat. (Kadir, 2017)

Desain Arduino dibuat sedemikian rupa dengan tujuan agar memudahkan setiap orang untuk membuat purwarupa perangkat elektronik. Arduino dapat dihubungkan dengan berbagai macam modul sensor dan modul komunikasi seperti Ethernet, WiFi serta beberapa modul output seperti layar LCD dan lain sebagainya. Arduino juga menggunakan pendekatan dan prinsip open-source pada perangkat kerasnya. Hal ini berarti bahwa setiap orang dapat mengembangkan rancangannya secara bebas walaupun menggunakan rancangan awal dari Arduino.

Dengan banyaknya mikrokontroler khususnya perangkat Arduino yang beredar dipasaran, maka sebagai pengguna perlu teliti dalam pemilihannya. Tipe mikrokontroler yang dipilih semestinya disesuaikan dengan kebutuhan. (Dharmawan, 2017)

Pemilihan ini idealnya didasarkan pada kebutuhan dari rancangan yang kita kembangkan. Sebagai contoh, kita tidak perlu menggunakan mikrokontroler seperti ATmega168 yang memiliki 14 pin IO atau bahkan ATmega2560 32bit dengan 54 pin IO apabila hanya bertujuan untuk menyalakan lampu secara otomatis karena hal sederhana tersebut dapat dilakukan hanya dengan menggunakan mikrokontroler ATtiny85 8bit yang memiliki 6 pin IO.

Arduino Uno (Gambar 4) mengandung IC (berupa atmel AVR) dan dilengkapi dengan oscillator $16 \mathrm{MHz}$ (yang memungkinkan operasi berbasis waktu dilaksanakan dengan tepat atau disebut dengan clock), dan regulator (pembangkit tegangan) 3 sampai 5 volt. 


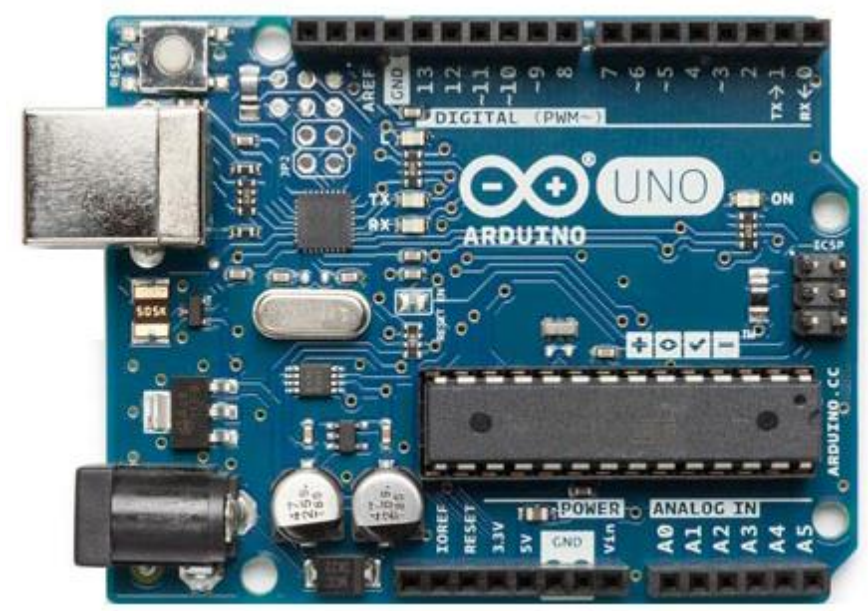

Gambar 4. Arduino Uno

Sumber : https://www.arduino.cc

Arduino dapat diprogram dengan perangkat lunak Arduino IDE (Integrated Development Environment). Pada IC yang tertanam pada papan Arduino terdapat bootloader yang difungsikan untuk pengunggahan kode baru. Arduino IDE merupakan aplikasi yang mencakup editor, compiler, dan uploader dapat menggunakan seri modul keluarga arduino, seperti Arduino Duemilanove, Uno, dan Mega. Arduino IDE memungkinkan untuk menulis, mengubah, dan mengkonversikan program menjadi kode-kode instruksi untuk selanjutnya diprogramkan kedalam papan Arduino. (Dharmawan, 2017)

Sensor adalah transducer yang berfungsi untuk mengolah masukan berupa variasi gerak, panas, cahaya atau sinar, magnetis, dan kimia menjadi tegangan serta arus listrik. Sensor berfungsi sebagai alat untuk mendeteksi dan juga untuk mengetahui gelombang magnitude. Transduser sendiri memiliki arti mengubah, resapan dari bahasa latin traducere. Bentuk perubahan yang dimaksud adalah kemampuan merubah suatu energi kedalam bentuk energi lain. Energi yang diolah bertujuan untuk menunjang kinerja piranti yang menggunakan sensor itu sendiri. Sensor sering digunakan dalam proses pendeteksi atau proses pengukuran. Sensor yang sering digunakan dalam berbagai rangkaian elektronik antara lain sensor cahaya, sensor suhu, sensor tekanan, sensor gerak, dan sensor sonar.

Sensor pada robot layaknya indera pada manusia atau binatang. Bagian ini berfungsi untuk menyampaikan kondisi yang ada disekitar robot kebagian otak sehingga robot dapat melakukan tindakan sesuai keadaan tersebut. (Widodo, 2015)

Sensor HC-SR04 (Gambar 5) merupakan modul sensor siap pakai, sebuah piranti yang berfungsi sebagai pengirim dan penerima gelombang ultrasonic. 


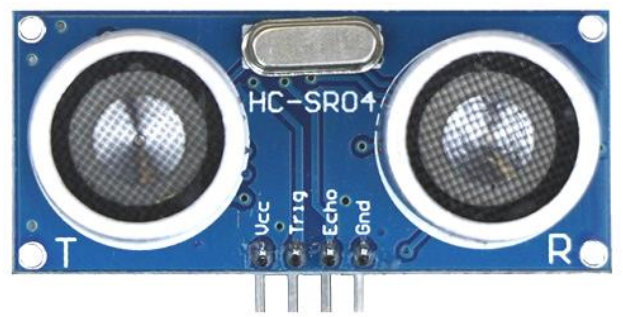

Gambar 5. Sensor sonar HC-SR04

Sensor HC-SR04 dapat mengukur jarak dalam rentang antara $2 \mathrm{~cm}$ sampai $4 \mathrm{~m}$, dimana akurasinya mencapai $3 \mathrm{~mm}$ dengan output panjang pulsa yang sebanding dengan jarak objek. Selain transmitter dan receiver, pada modul sensor ini terdapat juga control circuit. Sensor ini hanya memerlukan 2 pin I/O (input/output) untuk berkomunikasi dengan mikrokontroler, yaitu Trigger dan Echo. (Wicaksono \& Hidayat, 2017)

Cara kerja sensor HC-SR04 secara detail adalah sebagai berikut, gelombang dipancarkan oleh pemancar receiver sebanyak 8 kali. Untuk mengukur jarak benda, frekuensi yang umum digunakan sebesar $40 \mathrm{kHz}$. Gelombang yang terpancar akan merambat sebagai gelombang bunyi dengan kecepatan sebesar 340m/s. Ketika menyentuh suatu objek, maka gelombang tersebut akan dipantulkan. Setelah gelombang pantulan sampai di sensor penerima, maka gelombang berubah menjadi sinyal yang akan diproses untuk menghitung jarak objek tersebut.
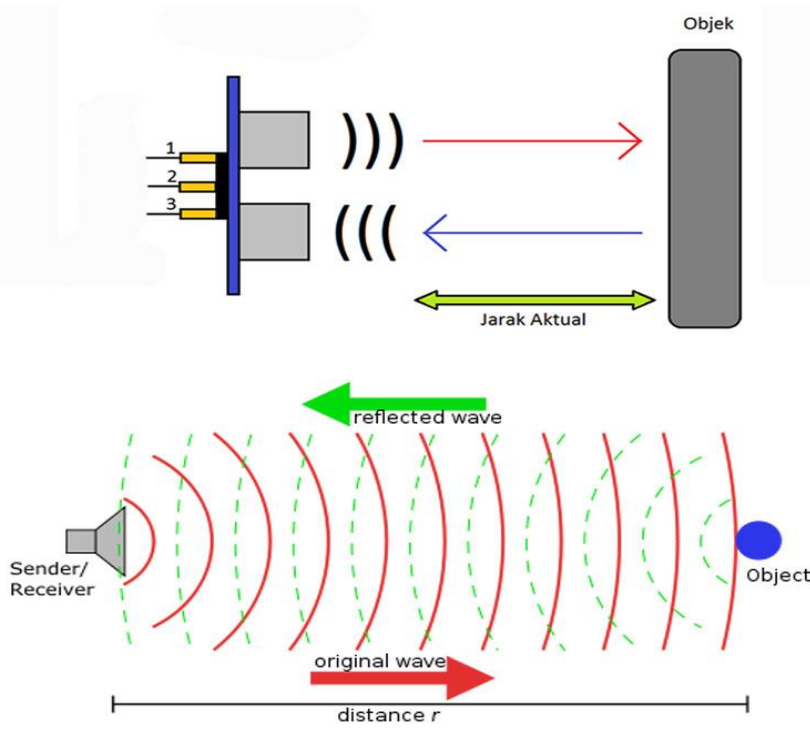

Gambar 6. Cara kerja sensor sonar

Sumber : https://www.elangsakti.com/2015/05/sensor-ultrasonik.html

Untuk mengukur jarak daripada objek bisa di hitung dengan rumus sebagai berikut:

$$
S=\frac{340 . t}{2}
$$


Dimana :

S : Jarak antara sensor ultrasonik dengan benda (bidang pantul).

t : Selisih antara waktu pemancaran gelombang (transmitter) dan waktu ketika gelombang pantul diterima (receiver).

340 : Nilai kecepatan suara.

Motor servo adalah sebuah motor DC yang dilengkapi rangkaian kendali dengan sistem closed feedback yang terintegrasi dalam motor tersebut. Motor servo Tower Pro adalah sebuah servo kecil dengan output power tinggi. Motor ini dapat berotasi sekitar 180 derajat (Wicaksono \& Hidayat, 2017). Bentuk fisik dari motor servo bisa dilihat pada gambar 7.

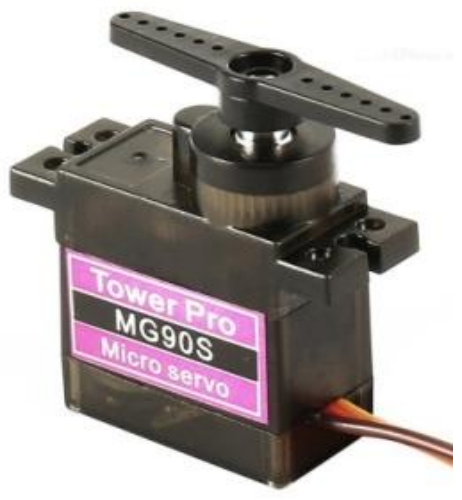

Gambar 7. Servo Tower Pro 180o

Motor servo disusun dari sebuah motor DC, gearbox, variabel resistor (VR) atau potensiometer dan rangkaian kontrol. Potensiometer berfungsi untuk menentukan batas maksimum putaran sumbu (axis) motor servo. Motor servo mampu bekerja pada dua arah dimana arah dan sudut pergerakan rotornya dapat dikendalikan dengan memberikan variasi lebar pulsa (duty cycle) sinyal PWM (Pulse Width Modulation) pada bagian pin kontrolnya.

Untuk membuat sebuah robot berkaki agar sesuai dengan tujuan yang akan dicapai maka dibutuhkan bagian-bagian yang sesuai fungsinya. Adapun bagian-bagian tersebut antara lain yaitu, catu daya; kontroler; sensor; motor; mekanik robot; dan komponen pendukung seperti pengkabelan dan pengisian daya.

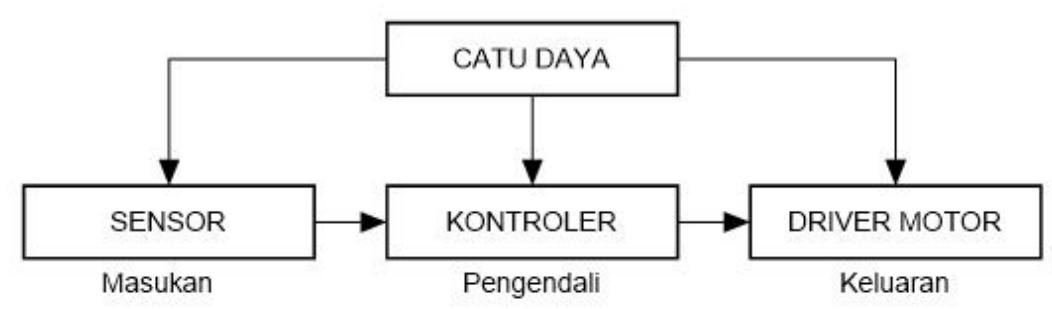

Gambar 8. Blok diagram umum sistem pergerakan robot 
Berikut penjelasan diagram pada gambar 8:

Masukan : Berupa sensor yang digunakan untuk memantau area sekitar robot.

Pengendali : Untuk melakukan pengendalian gerakan ke aktuator, menyalurkan serta memproses informasi yang masuk dari sensor sehingga didapat data-data yang sesuai untuk dapat menggerakkan motor.

Keluaran : Bagian ini yaitu motor servo sebagai penggerak kaki robot agar bisa bergerak maju, mundur, belok kekiri, belok kekanan, bergeser kekiri, bergeser kekanan.

Catu daya : Pada bagian ini merupakan sumber tegangan listrik untuk mengsuplai daya listrik ke seluruh komponen elektronik yang terhubung.

\section{HASIL DAN PEMBAHASAN}

Secara garis besar perangkat keras robot terdiri dari dua bagian yaitu komponen mekanik dan komponen elektronik. Komponen mekanik, berupa bahan besi, plastik, lem dan bahan lainnya yang digunakan untuk membuat badan robot (mekanik robot). Komponen elektorik, berupa alat-alat atau perangkat elektronik antara lain, Arduino ATmega328; Arduino Sensor Shield; TP4056; Sensor HC-SR04; Motor Servo 180; Li-Po Battery 3.7 Volt 1500mAh; Saklar 0/1; pengkabelan (wire).

Mekanik robot meliputi bentuk atau dimensi robot mulai dari kaki sampai pada badan robot dan didesain sesuai bentuknya yaitu robot laba-laba. Pembuatan mekanik robot dilakukan pada tahap awal perancangan hardware agar setiap komponen elektronik bisa ditempatkan pada posisi yang tepat.
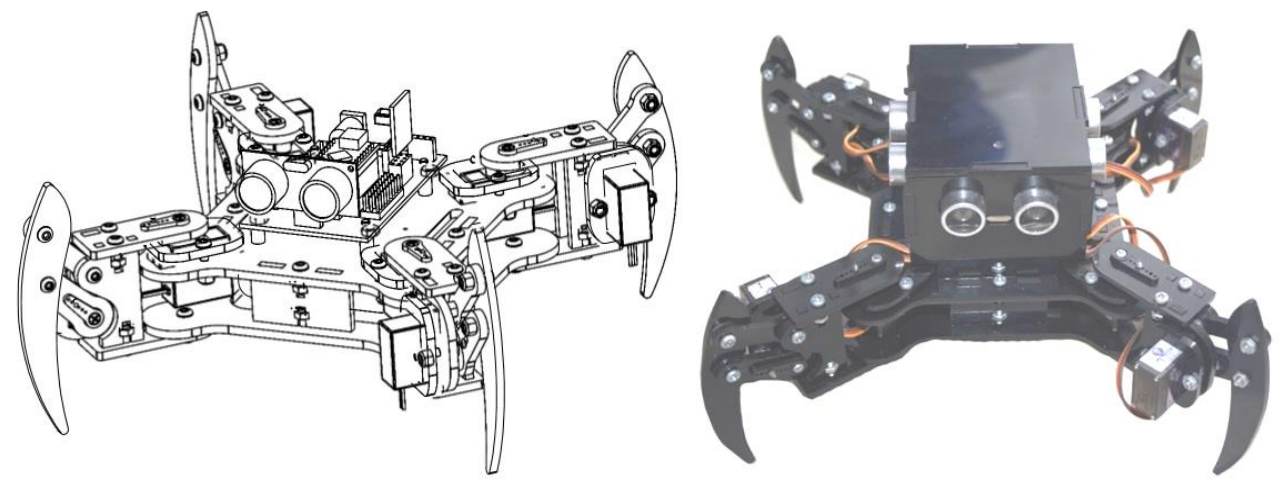

Gambar 9. Desain mekanik robot laba-laba

Kontroler meliputi rangkaian elektronik berupa papan sirkuit Arduino, dimana papan ini menjadi pusat koneksi dari komponen-komponen elektronika lainnya. Motor servo dipasangkan pada sendi dari tiap kaki robot. Sensor meliputi komponen sensor HC-SR04 
yang ditempatkan di sisi depan, kiri dan sisi kanan robot seperti di jelaskan pada gambar 10. Catu daya berupa komponen baterai 3.7 Volt $1500 \mathrm{mAh}$ sebagai sumber tegangan. Pada bagian ini juga terdapat modul TP4056 sebagai perangkat untuk pengisian daya pada baterai. Desain komponen elektronik robot dibuat agar setiap komponen bisa bekerja dengan baik dan tidak terjadi kebakaran atau kerusakan pada komponen yang ada.

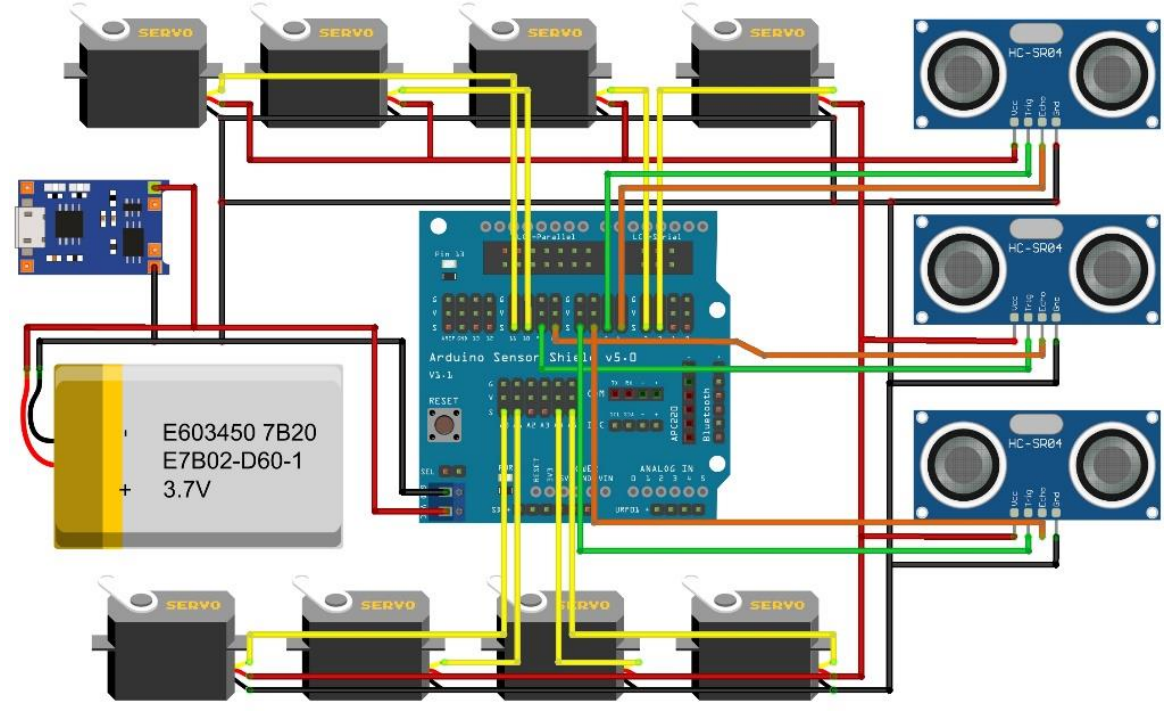

Gambar 10. Skema pengkabelan komponen elektronik

Dapat dilihat dari gambar 10, setiap komponen terhubung ke papan sirkuit (sensor shield). Sensor shield terhubung dengan cara ditancapkan langsung pada papan Arduino.

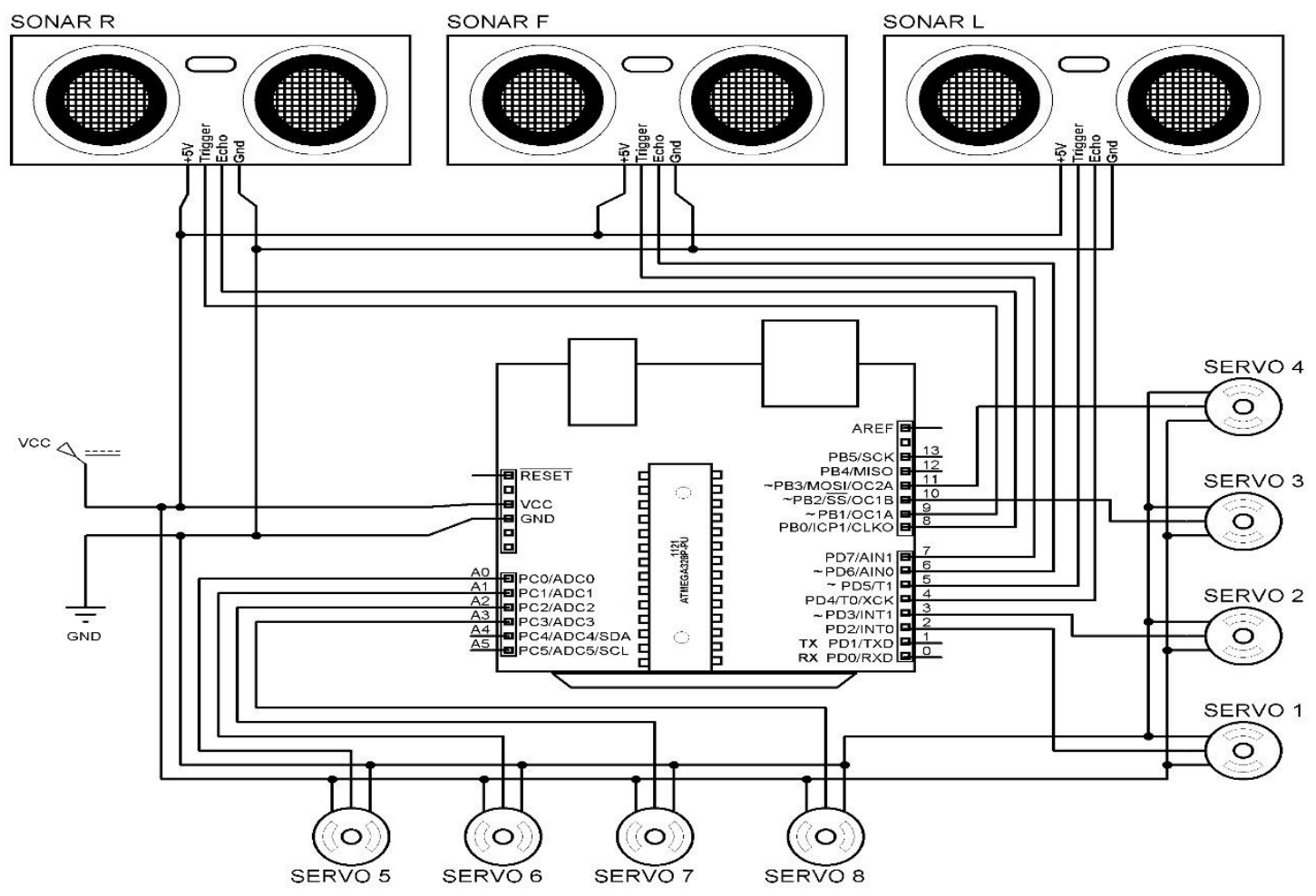

Gambar 11. Skema komponen elektronik robot laba-laba 
Pengujian sistem gerak pada Robot dilakukan dengan menjalankan robot pada bidang datar secara bebas (random). Berikut adalah tahapan pengujian sistem gerak pada robot:

Pengujian gerak robot berjalan bebas (tanpa penghalang). Pengujian ini dilakukan dengan cara menjalankan robot pada lintasan sepanjang 2 meter dengan kecepatan gerak servo mulai dari $7 \mathrm{~ms}$ (paling lambat) hingga $3 \mathrm{~ms}$ (paling cepat).

Tabel 1. Hasil pengujian robot berjalan bebas

\begin{tabular}{|l|l|l|}
\hline Kecepatan Servo & Jarak Tempuh & Waktu Tempuh \\
\hline $7 \mathrm{~ms}$ & $2 \mathrm{~m}$ & $19,5 \mathrm{~s}$ \\
\hline $6 \mathrm{~ms}$ & $2 \mathrm{~m}$ & $17,67 \mathrm{~s}$ \\
\hline $5 \mathrm{~ms}$ & $2 \mathrm{~m}$ & $16,50 \mathrm{~s}$ \\
\hline $4 \mathrm{~ms}$ & $2 \mathrm{~m}$ & $15,96 \mathrm{~s}$ \\
\hline $3 \mathrm{~ms}$ & $2 \mathrm{~m}$ & $15,69 \mathrm{~s}$ \\
\hline
\end{tabular}

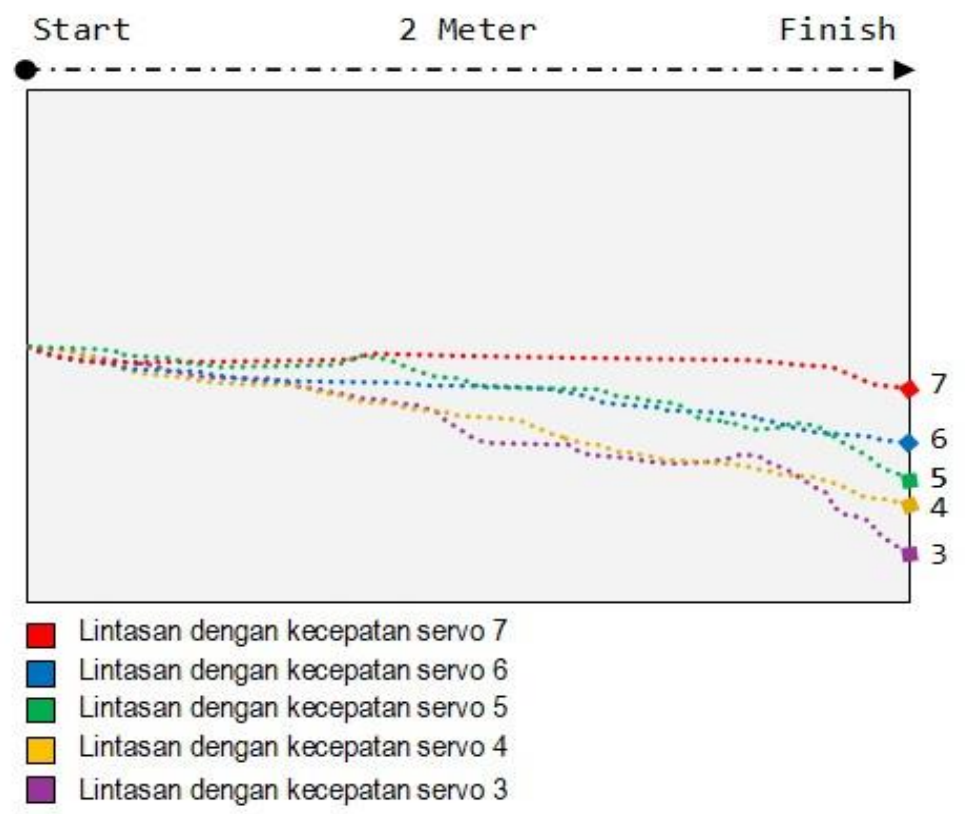

Gambar 12. Lintasan robot secara random

Dilihat dari hasil pengujian pada gambar 12. bahwa titik akhir yang di tuju tidak sama. Hal ini terjadi karena robot bergerak berjalan secara acak (random) dan dipengaruhi oleh kecepatan servo.

Pengujian gerak robot menghindar halangan dilakukan dengan menjalankan robot pada bidang datar dan meletakkan beberapa penghalang atau benda dan mengamati tindakan robot saat mendeteksi halangan. 


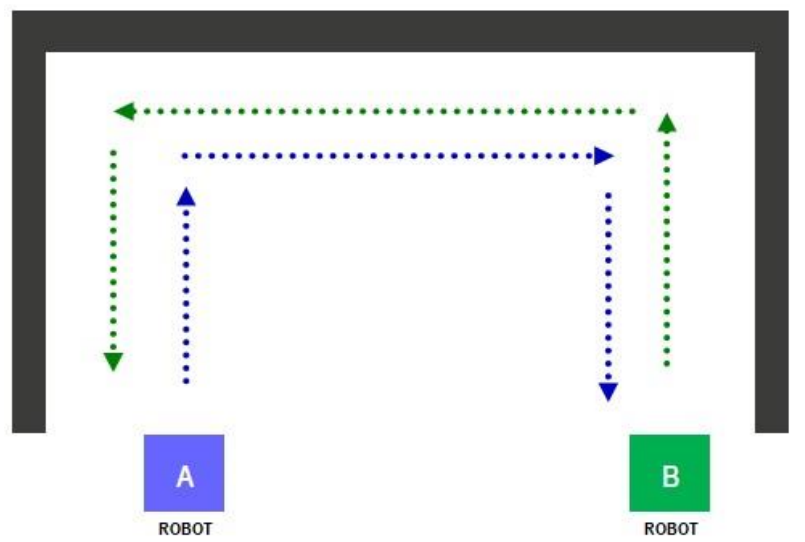

Gambar 13. Gerak robot menghindar halangan dengan cara berbelok

Robot A : Robot berjalan dan mendeteksi adanya halangan pada sisi depan, pada saat yang sama pula robot mendeteksi jarak halangan pada sisi kiri lebih dekat dari sisi kanan maka robot bergerak mudur lalu berbelok ke kanan. Robot B : Robot berjalan dan mendeteksi halangan pada sisi depan, pada saat yang sama robot mendeteksi jarak halangan pada sisi kanan lebih dekat dari jarak pada sisi kiri maka robot bergerak mundur lalu berbelok ke kiri.

Pengujian robot menelusuri maze (labirin), dilakukan dengan menjalankan robot pada suatu jalur labirin (maze) mulai dari garis start sampai garis finish.

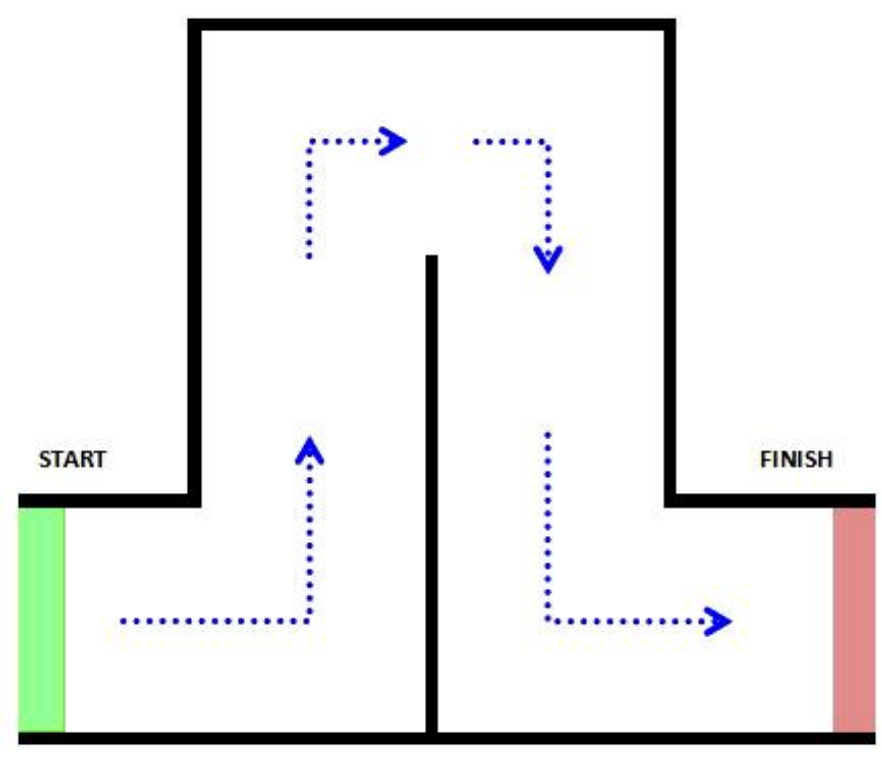

Gambar 14. Peta jalur labirin (maze)

Dari hasil pengujian pada tahap ini, robot sudah bisa bekerja sesuai sistem yang dibangun namun ditemukan adanya beberapa tabrakan. Tabrakan terjadi dikarenakan rancangan sensor yang dibuat hanya bisa mendeteksi halangan pada sisi depan dan samping, ketika halangan berada pada area blank spot maka sensor tidak dapat mendeteksi halangan tersebut. 


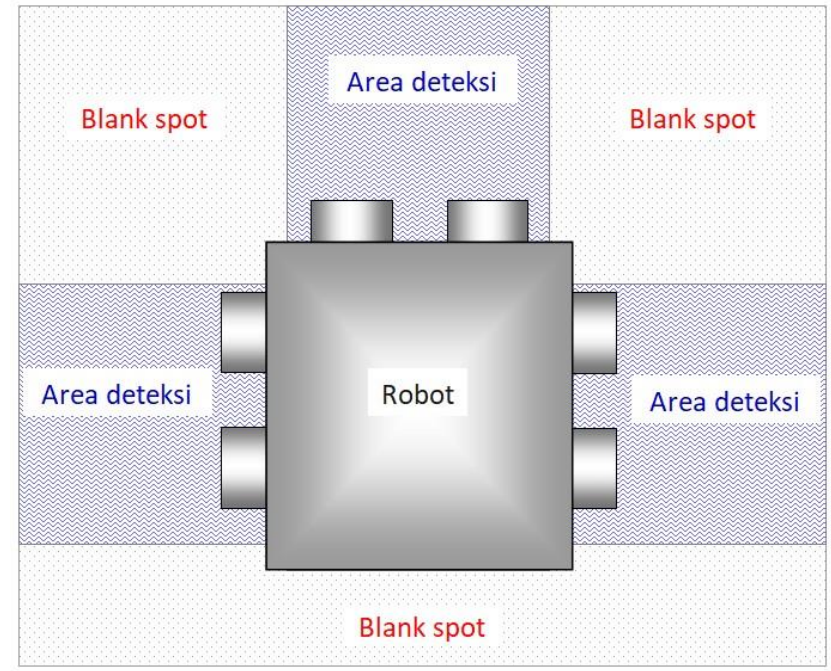

Gambar 15. Area pendeteksian objek di sekitar robot

Dilihat dari gambar 15, bahwa terdapat beberapa area blank spot yang mengakibatkan tidak terdeteksinya benda/halangan di area tersebut. Tabrakan juga terjadi dikarenakan adanya penurunan performa pada komponen elektronik, jika dinyalakan dalam jangka waktu yang cukup lama maka secara perlahan terjadi penurunan fungsi kerja secara keseluruhan pada komponen elektronika.

Beberapa faktor yang mempengaruhi penurunan performa pada komponen elektronika antara lain yaitu, kapasitas baterai yang dipakai yaitu sebsar $1500 \mathrm{mAh}$ dengan tegangan 3.7 Volt hanya bertahan selama kurang dari satu jam pemakaian. Ketika energi pada baterai kurang dari $50 \%$ maka terjadi penurunan tegangan, berakibat pada penurunan performa robot.

\section{KESIMPULAN DAN REKOMENDASI}

Sistem gerak pada pada robot sudah bekerja dengan baik dan robot sudah bisa berjalan secara random pada area bidang datar (tanpa halangan). Sistem sensor pada robot juga sudah bekerja dan mampu mendeteksi halangan disekitar robot. Perangkat lunak yang di tanamkan pada mikrokontroler sudah bisa membaca data yang diperoleh melaui sensor dan memproses data tersebut sehingga menghasilkan suatu instruksi untuk mengatur pergerakan motor servo. Secara keseluruhan, sistem pengontrolan gerak yang diterapkan bekerja sesuai program yang di tanamkan pada mikrokontroler, namun masih terjadi tabrakan pada saat posisi halangan/benda berada pada area blank spot atau area diluar jangkauan gelombang ultrasonic yang di pancarkan oleh sensor melalui transmiter. Apabila robot dijalankan terus menerus dalam waktu yang lama, maka terjadi penurunan performa pada keseluruhan komponen elektronik. Hal ini terjadi karena energi pada baterai sifatnya tebatas pada kapasitas baterai yang dipakai yaitu $1500 \mathrm{mAh}$. Ketika energi pada baterai 
kurang dari 50\%, maka terjadi penurunan tegangan listrik sehingga kerja komponen elektronik menjadi tidak stabil.

Adapun rekomendasi yang dapat disampaikan pada penelitian ini ialah sebagai berikut, untuk memperluas area pendeteksian objek, bisa ditambahkan beberapa sensor tambahan pada sisi belakang dan sisi dimana terdapat area blank spot. Memperbaiki desain mekanik pada ketinggian kaki robot agar disesuaikan dengan posisi sensor sehingga tidak menghalangi area kerja sensor. Untuk menjaga kestabilan performa dari komponen elektronik dalam waktu yang lebih lama, maka perlu menambahkan kapasitas baterai.

\section{REFERENSI}

Arasada, B., \& Suprianto, B. (2017). Aplikasi Sensor Ultrasonik Untuk Deteksi Posisi Jarak Pada Ruang Menggunakan Arduino Uno. Jurnal Teknik Elektro.

Dharmawan, H. A. (2017). Mikrokontroler Konsep Dasar dan Praktis. Malang: UB Press.

Febriani, R. (2010). Aplikasi Metoda Random Walks untuk kontrol Gerak Robot Berbasis Citra. Jurnal Kelompok Keahlian FIsika Teoriti Energi Tinggi dan Instrumentasi.

Kadir, A. (2017). Pemrograman Arduino dan Android Menggunakan App Inventor. Jakarta: PT. Elek Media Komputindo.

Kausar, A. (2014). Robot Pencari Alamat Menggunakan Warna. Jurnal Media Infotama.

Lufita. (2016). Robot Multi Sensor Sebagai Media Pembelajaran Mata Kuliah Sensor dan Aktuator.

Salahuddin, S., \& Mellyssa, W. (2018). Perancangan Robot Laba-Laba Pendeteksi Api Berbasis Mikrokontroller ATmega328. Elkawnie Journal of Islamic Science and Technology.

Wicaksono, M., \& Hidayat. (2017). Mudah Belajar Mikrokontroler Arduino. Jakarta.

Widodo, B. (2015). Proyek Robot Spektakuler. Jakarta: Elex Media Komputindo. 